\title{
Filosofia no Novo Ensino Médio: BNCC e os 17 Objetivos de Desenvolvimento Sustentável
}

\author{
Philosophy in New High School: BNCC and the 17 Sustainable \\ Development Goals
}

\section{Erica Cristina Frau}

Professora mestra pela Universidade Estadual de Campinas, Campinas, SP, Brasil. ericafrau@gmail.com - https://orcid.org/0000-0002-5140-0093

\section{Paulo Rogério da Silva}

Professor mestre pela Universidade de São Paulo, São Paulo, SP, Brasil.

paulo_quimica@professor.sp.gov.br - https://orcid.org/0000-0003-2480-5113

\section{Daniel José de Araujo}

Professor mestre pela União dos Cursos Superiores SEB, Ribeirão Preto, SP, Brasil. djarjfr@yahoo.com.br - https://orcid.org/0000-0003-3111-6535

Recebido em 28 de fevereiro de 2021

Aprovado em 18 de julho de 2021

Publicado em 30 de dezembro de 2021

RESUMO: Este artigo tem como objetivo apontar algumas reflexões sobre as mudanças ocorridas no Novo Ensino Médio, mais especificamente na estrutura do Ensino de Filosofia a partir da homologação da BNCC em 2018, e estabelecer as relações entre os componentes curriculares da Área de Ciências Humanas e Sociais Aplicadas, e da Área de Ciências da Natureza e suas Tecnologias. Para isso, são apresentados alguns aspectos essenciais da Declaração Universal dos Direitos Humanos (DUDH) e dos 17 Objetivos de Desenvolvimento Sustentável (ODS) propostos pela Organização das Nações Unidas (ONU), e a integração dessas áreas a partir das escolhas dos estudantes e da flexibilização dessa nova estrutura para o Ensino Médio por meio dos Itinerários Formativos. Por fim, apresentamos algumas reflexões sobre como as especificidades do ensino de Filosofia poderão resistir no Novo Ensino Médio, resgatando a condição humana e a importância da Declaração Universal dos Direitos Humanos (DUDH) para assegurar essa articulação.

Palavras-chave: Áreas de Conhecimento; BNCC; Ensino Médio; Filosofia; 17 ODS.

ABSTRACT: This article aims to point out some reflections on the changes that took place in the New High School, more specifically in the structure of Philosophy Teaching from the approval of the BNCC in 2018, and to establish the relationships between the curriculum components of the Areas of Applied Social and Human Sciences, and Natural Sciences and its Technologies. In this context, some essential aspects of the Universal Declaration of Human Rights (UDHR) and the 17 Sustainable 
Development Goals (SDGs) proposed by the United Nations (UN) are presented, as well as the integration of these areas based on student choices and flexibility; this new structure of High School was carried out through Formative Itineraries. Finally, we present some reflections on how the specificities of Philosophy teaching can resist in the New High School, rescuing the human condition and the importance of the Universal Declaration of Human Rights (UDHR) to ensure this articulation.

Keywords: Knowledge Areas; BNCC; High school; Philosophy; 17 SDGs.

\section{Introdução}

No final de dezembro do ano de 2018, a Base Nacional Comum Curricular (BNCC), etapa do Ensino Médio, foi finalmente homologada. Essa nova proposição trouxe mudanças significativas na estrutura do Ensino Médio e no ensino de Filosofia em todo Brasil. Nesse contexto, este artigo tem como objetivo geral apontar algumas reflexões sobre as mudanças e estabelecer relações entre os componentes curriculares da Área de Ciências Humanas e Sociais Aplicadas, e da Área de Ciências da Natureza e suas Tecnologias.

Para estabelecer essas relações, surgiram algumas questões que nortearam a pesquisa e a estruturação deste artigo, sendo elas: a) quais são as principais mudanças na nova estrutura do Ensino Médio?; b) como o ensino de filosofia está presente na estrutura da Base Nacional Comum Curricular (BNCC);c) quais são os aspectos essenciais da Declaração Universal dos Direitos Humanos (DUDH) e dos 17 Objetivos de Desenvolvimento Sustentável (ODS) propostos pela Organização das Nações Unidas (ONU) na Agenda 2030.

Para responder essas questões, foi necessário utilizar como metodologia a análise documental, por meio da consulta e análise de documentos oficiais (resoluções, decretos e leis) publicados em Diário Oficial, portais governamentais, livros e artigos publicados em revistas.

Neste contexto, organizamos o artigo em quatro partes. Na primeira parte abordaremos o ensino da Filosofia na estrutura da Base Nacional Comum Curricular (BNCC). Na segunda parte, falaremos das escolhas dos estudantes e da flexibilização dessa nova estrutura por meio dos Itinerários Formativos. Na terceira, dissertaremos sobre a integração das Áreas por meio dos 17 Objetivos de Desenvolvimento Sustentável (ODS). Na última parte, apresentaremos reflexões 
sobre como as especificidades do ensino de Filosofia poderão resistir no Novo Ensino Médio, resgatando a condição humana e a importância da Declaração Universal dos Direitos Humanos (DUDH) para assegurar essa articulação.

\title{
O ensino de Filosofia na estrutura da BNCC
}

O ensino de Filosofia, a partir da Base Nacional Comum Curricular (BNCC) sofre mudanças significativas, sendo a primeira delas na estrutura de Área de Ciências Humanas e Sociais Aplicadas. Se nos documentos orientadores anteriores tínhamos pontualmente marcado o componente curricular de Filosofia na Área, hoje, temos a sua presença garantida juntamente com os componentes de Geografia, História e Sociologia.

\begin{abstract}
A BNCC da área de Ciências Humanas e Sociais Aplicadas - integrada por Filosofia, Geografia, História e Sociologia - propõe a ampliação e o aprofundamento das aprendizagens essenciais desenvolvidas no Ensino Fundamental, sempre orientada para uma formação ética. Tal compromisso educativo tem como base as ideias de justiça, solidariedade, autonomia, liberdade de pensamento e de escolha, ou seja, a compreensão e o reconhecimento das diferenças, o respeito aos direitos humanos e à interculturalidade, e o combate aos preconceitos de qualquer natureza. (BRASIL, 2018, p. 561)
\end{abstract}

O excerto é o primeiro trecho do texto da Área de Ciências Humanas e Sociais Aplicadas. A partir dele, fica evidente que os quatro componentes curriculares estão a serviço da ampliação e do aprofundamento dos saberes que foram iniciados no Ensino Fundamental. Essa informação deve causar, nos docentes e pesquisadores, um certo estranhamento, uma vez que Filosofia e Sociologia são componentes novos nessa etapa da educação básica.

Porém, o espanto não para por aí: a Filosofia está integrada com os outros três componentes a partir das seis Competências Específicas de Ciências Humanas e Sociais Aplicadas, que se desdobram em trinta e duas habilidades específicas, todas envolvendo os quatro componentes curriculares da Área. Ao analisar cada uma dessas habilidades, é possível perceber o quanto cada uma delas é abrangente e se desdobram em inúmeras possibilidades. Sendo assim, é preciso destacar que o 
ensino de Filosofia está na tomada de decisão de cada Estado do país, que construirá o seu Currículo de acordo com os seus interesses e suas perspectivas.

Ao elaborar os Currículos, os Estados deverão assegurar a presença de cada componente curricular por meio de objetos de conhecimentos que se desenvolverão a partir de cada habilidade ${ }^{1}$. Somente a partir da elaboração desses organizadores (quadros que distribuem as competências, as habilidades e os objetos de conhecimento de cada componente curricular) é que saberemos como se dará o ensino de Filosofia. Posteriormente a essa organização, com os Currículos já homologados pelos Conselhos Estaduais, conheceremos a nova identidade do ensino de Filosofia em cada Estado do Brasil.

Toda essa estrutura compõe a Parte Comum da BNCC e se refere à carga horária total mínima de 1.800 horas. Contudo, o cenário de mudanças não para. Com a implementação ocorre também a inserção de Itinerários Formativos, apresentados por meio do Art. $4^{\circ}$ da lei $n^{\circ} 13.415 / 2017$, como podemos conferir:

\footnotetext{
Art. $4^{\circ} \mathrm{O}$ art. 36 da Lei $\mathrm{n}^{\circ} 9.394$, de 20 de dezembro de 1996, passa a vigorar com as seguintes alterações:

"Art. 36. O currículo do ensino médio será composto pela Base Nacional Comum Curricular e por itinerários formativos, que deverão ser organizados por meio da oferta de diferentes arranjos curriculares, conforme a relevância para o contexto local e a possibilidade dos sistemas de ensino, a saber:

I - linguagens e suas tecnologias;

II - matemática e suas tecnologias;

III - ciências da natureza e suas tecnologias;

IV - ciências humanas e sociais aplicadas;

$V$ - formação técnica e profissional. [...]

(BRASIL, grifo nosso, 2017)
}

Conforme preveem as Diretrizes Nacionais para o Ensino Médio ${ }^{2}$, o anexo da Portaria $n^{\circ} 1.432 / 2018$ estabelece os referenciais para elaboração dos Itinerários Formativos, e podemos conferir no excerto abaixo que esses irão compor um

[...] conjunto de situações e atividades educativas que os estudantes podem escolher conforme seu interesse, para aprofundar e ampliar aprendizagens em uma ou mais Áreas de Conhecimento e/ou na Formação Técnica e Profissional, com carga horária total mínima de 1.200 horas. (BRASIL, 2018) 
Logo, o ensino de Filosofia, dentro da Área de Ciências Humanas e Sociais Aplicadas, terá dois momentos para acontecer: a partir da formação geral básica, que compõem as 1.800 horas, e por meio dos Itinerários Formativos, que comporão as 1.200 horas. O que corresponde às 3.000 horas da carga horária total das três séries do Ensino Médio. Dada essa estrutura, nos perguntamos: quanto desse tempo será destinado ao ensino de Filosofia e como as suas especificidades serão garantidas?

\section{A flexibilização e as escolhas dos estudantes}

Com a homologação da Base Nacional Comum Curricular (BNCC), o ensino da Filosofia e dos demais componentes curriculares das Ciências Humanas correm risco de esvaziamento a partir da flexibilização ofertada pelos Itinerários Formativos. Nessa nova estrutura proposta, os estudantes do Ensino Médio só terão acesso obrigatório à Área de Ciências Humanas e Sociais Aplicadas na primeira série, depois, os saberes dessa Área só serão garantidos se houver a oferta do Itinerário Formativo que a contemple, e se os estudantes escolherem tal Itinerário Formativo, ou então, se os Estados garantirem outros arranjos.

[...] De que escolha estamos falando, quem poderá escolher? É interessante observar que o aluno não poderá escolher uma formação sólida geral nem necessariamente terá a possibilidade de escolher entre os cinco itinerários formativos, já que sua oferta dependerá das propostas e condições concretas de cada estado e de cada escola. (KRAWCZYK, N.; FERRETI, C, 2017, p. 38 e 39)

Certamente faltarão opções de escolha para os jovens mediante a realidade apresentada. Nesse sentido, pensar sobre a flexibilidade do Ensino Médio é mais do que necessário, tendo em vista que essa etapa da educação básica é determinante no futuro dos jovens estudantes. A falta de opção pode ser entendida como um grande problema e dependendo do contexto educacional, social, político e econômico, é altamente possível que haja ampliação das desigualdades sociais. $O$ estudante, dependendo de suas escolhas, ou melhor, das opções de escolhas que 
Ihe serão oferecidas, poderá ficar vulnerável e ter seu futuro, seja ele profissional ou acadêmico, comprometido.

[...] ao permitir, por exemplo, que os sistemas de ensino venham a predestinar ou induzir por avaliações/orientações vocacionais apenas uma parte dos jovens para ter contato com os componentes desta área, impedindo que tenham uma formação comum, com acesso ampliado e/ou aprofundado aos conhecimentos referentes a outras áreas. Assim, também, com os estudantes que optarem por outro itinerário formativo, que perderão contato mais efetivo com as C.H. (SIMÕES, W, 2017, p. 54)

Em suma, questionamos se a flexibilidade que aparece na proposta de mudança respeita os interesses e as diferenças de aprendizagem necessárias para a formação do indivíduo. O Art. 35-A da lei n 13.415 aponta que:

$\S 7^{\circ}$ Os currículos do ensino médio deverão considerar a formação integral do aluno, de maneira a adotar um trabalho voltado para a construção de seu projeto de vida e para sua formação nos aspectos físicos, cognitivos e socioemocionais. (BRASIL, 2017)

Sendo assim, torna-se essencial respeitar os diferentes interesses de aprendizagens. Devemos estar com o olhar atento para essas padronizações e homogeneizações, acompanhando o quanto elas poderão ser prejudiciais ao ensino de Filosofia e da Área de Ciências Humanas e Sociais Aplicadas.

Só o tempo revelará como serão as mudanças do Novo Ensino Médio, possibilitando assim a compreensão das intenções e dos caminhos que serão trilhados. O nosso desejo é ver uma educação singular que respeita a igualdade e as diferenças, que viabiliza acessos, inclusive aos saberes específicos da Filosofia e das Ciências Humanas nos Itinerários Formativos. 


\section{Os 17 Objetivos de Desenvolvimento Sustentável e a integração das Áreas de Ciências Humanas e Sociais Aplicadas e Ciências da Natureza e suas Tecnologias}

As mudanças do Novo Ensino Médio fomentam o trabalho interdisciplinar e transdisciplinar. A Base Nacional Comum Curricular (BNCC), por meio das 10 Competências Gerais Básicas (Figura 1) apontam para esse caminho propondo:

[...] a superação da fragmentação radicalmente disciplinar do conhecimento, o estímulo à sua aplicação na realidade, a importância do contexto para dar sentido ao que se aprende e o protagonismo do estudante em sua aprendizagem e na construção de seu projeto de vida. (BRASIL, 2018, p. 15)

Figura 1 - Competências Gerais BNCC

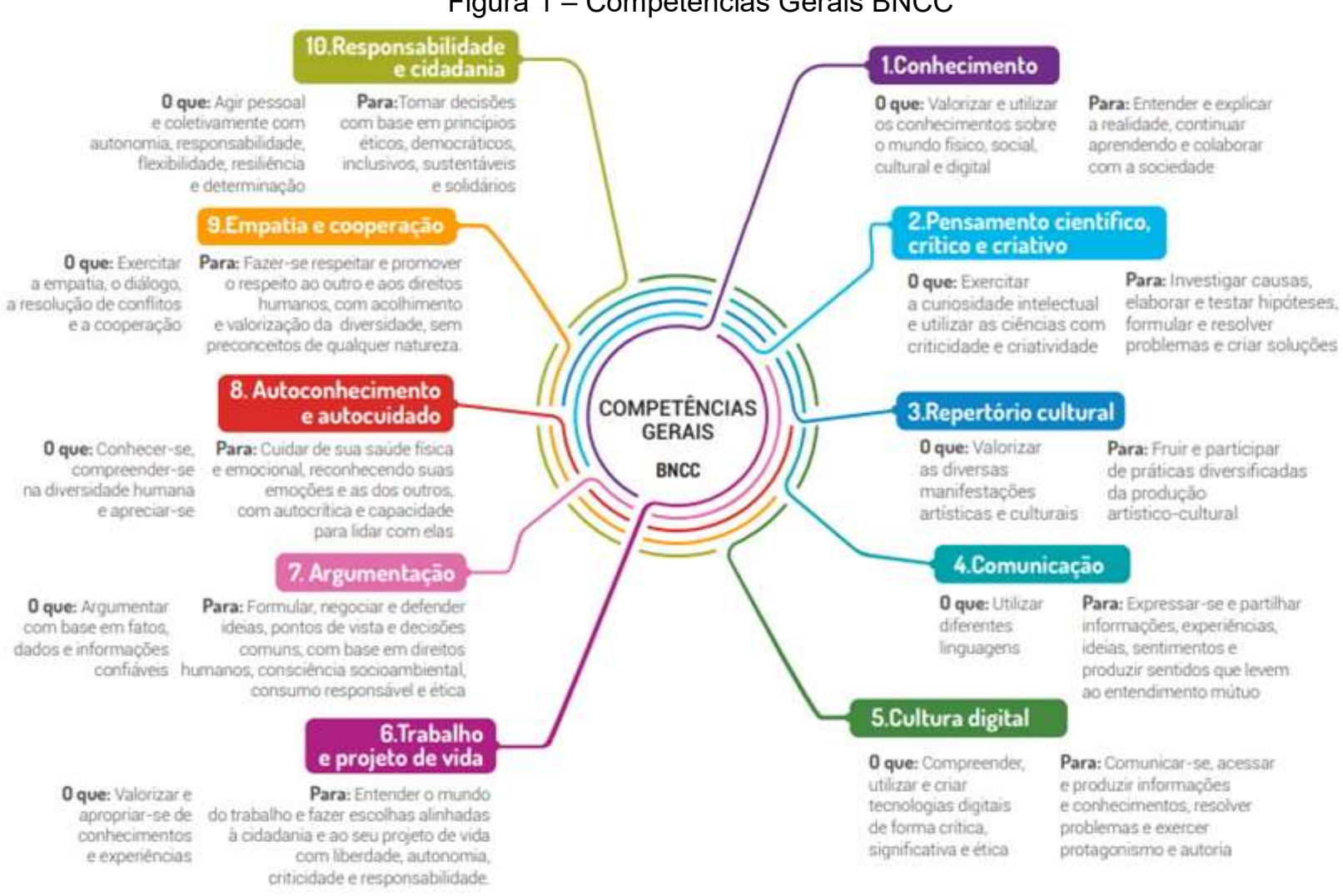

Fonte: Movimento pela Base Nacional Comum. Dimensões e Desenvolvimento das Competências Gerais da BNCC. Brasília, DF, 2018. 
Para a construção do projeto de vida, é de fundamental importância que os estudantes sejam capazes de fazer escolhas responsáveis e conscientes, em diálogo com seus desejos. Portanto, os Itinerários Formativos podem auxiliá-los nesta construção; eles

[...] são o conjunto de disciplinas, projetos, oficinas, núcleos de estudo, entre outras situações de trabalho, que os estudantes poderão escolher no ensino médio. Os itinerários formativos podem se aprofundar nos conhecimentos de uma área do conhecimento (Matemáticas e suas Tecnologias, Linguagens e suas Tecnologias, Ciências da Natureza e suas Tecnologias e Ciências Humanas e Sociais Aplicadas) e da formação técnica e profissional (FTP) ou mesmo nos conhecimentos de duas ou mais áreas e da FTP. (PORTAL MEC - Disponível em: http://portal.mec.gov.br/publicacoes-para-professores/30000-

uncategorised/40361-novo-ensino-medio-duvidas. Acesso em: 28 fev. 2021.)

A Base Nacional Comum Curricular (BNCC) aponta para o aprofundamento do conhecimento por meio do desenvolvimento dos Itinerários Formativos envolvendo duas ou mais áreas do conhecimento e, nesse contexto, os 17 Objetivos do Desenvolvimento Sustentável (ODS) podem ser compreendidos como essenciais para promover a integração das Áreas de Ciências Humanas e Sociais Aplicadas e Ciências da Natureza e Suas Tecnologias. Antes de estabelecer a integração entre essas duas áreas por meio dos ODS, consideramos importante apresentar a Agenda 2030 para o Desenvolvimento Sustentável, que expõe as intenções desses 17 objetivos.

Adotada em setembro de 2015 por 193 Estados Membros da ONU (UN General Assembly Resolution 70/1), a Agenda 2030 para o Desenvolvimento Sustentável resultou de um processo global participativo de mais de dois anos, coordenado pela ONU, no qual governos, sociedade civil, iniciativa privada e instituições de pesquisa contribuíram através da Plataforma 'My World'. Sua implementação teve início em janeiro de 2016, dando continuidade à Agenda de Desenvolvimento do Milênio (2000-2015), e ampliando seu escopo. Abrange o desenvolvimento econômico, a erradicação da pobreza, da miséria e da fome, a inclusão social, a sustentabilidade ambiental e a boa governança em todos os níveis, incluindo paz e segurança. (Agenda 2030 - Disponível em: http://www.agenda2030.com.br/. Acesso em: 28 fev. 2021.) 
A Agenda 2030 para o Desenvolvimento Sustentável é composta por quatro partes principais: Declaração, Objetivos do Desenvolvimento Sustentável, Acompanhamento e Avaliação da Agenda 2030 e Implementação. A Declaração contém a visão, os princípios e os compromissos da Agenda 2030. Ela prevê um mundo livre de pobreza, miséria, fome, doença, violência, desigualdades, desemprego, degradação ambiental, esgotamento dos recursos naturais, entre outros. Os Objetivos do Desenvolvimento Sustentável reafirmam o compromisso com os Direitos Humanos, incluindo o direito ao desenvolvimento e o direito internacional.

São 17 objetivos e 169 metas de ação global para alcance até 2030 , em sua maioria, abrangendo as dimensões ambiental, econômica e social do desenvolvimento sustentável, de forma integrada e inter-relacionada. Guiados pelas metas globais, espera-se que os países definam as suas metas nacionais, de acordo com as suas circunstâncias, e as incorporem em suas políticas, programas e planos de governo. (Agenda 2030 Disponível em: http://www.agenda2030.com.br/. Acesso em: 28 fev. 2021.)

A Implementação da Agenda 2030 para o Desenvolvimento Sustentável pode ser vista nos objetivos e nas metas que tratam dos meios necessários para a execução da Agenda, que exigirá parcerias e solidariedade na mobilização de recursos, assim como engajamento entre governos, setor privado, sociedade civil e o Sistema ONU. Nesse contexto, os 17 ODS (Figura 2) e suas 169 metas da Agenda 2030 para o Desenvolvimento Sustentável podem auxiliar na construção dos Itinerários Formativos integrando as Áreas de Ciências Humanas Sociais e Aplicadas com Ciências da Natureza e Suas Tecnologias 
Figura 2 - Os Objetivos de Desenvolvimento Sustentável no Brasil
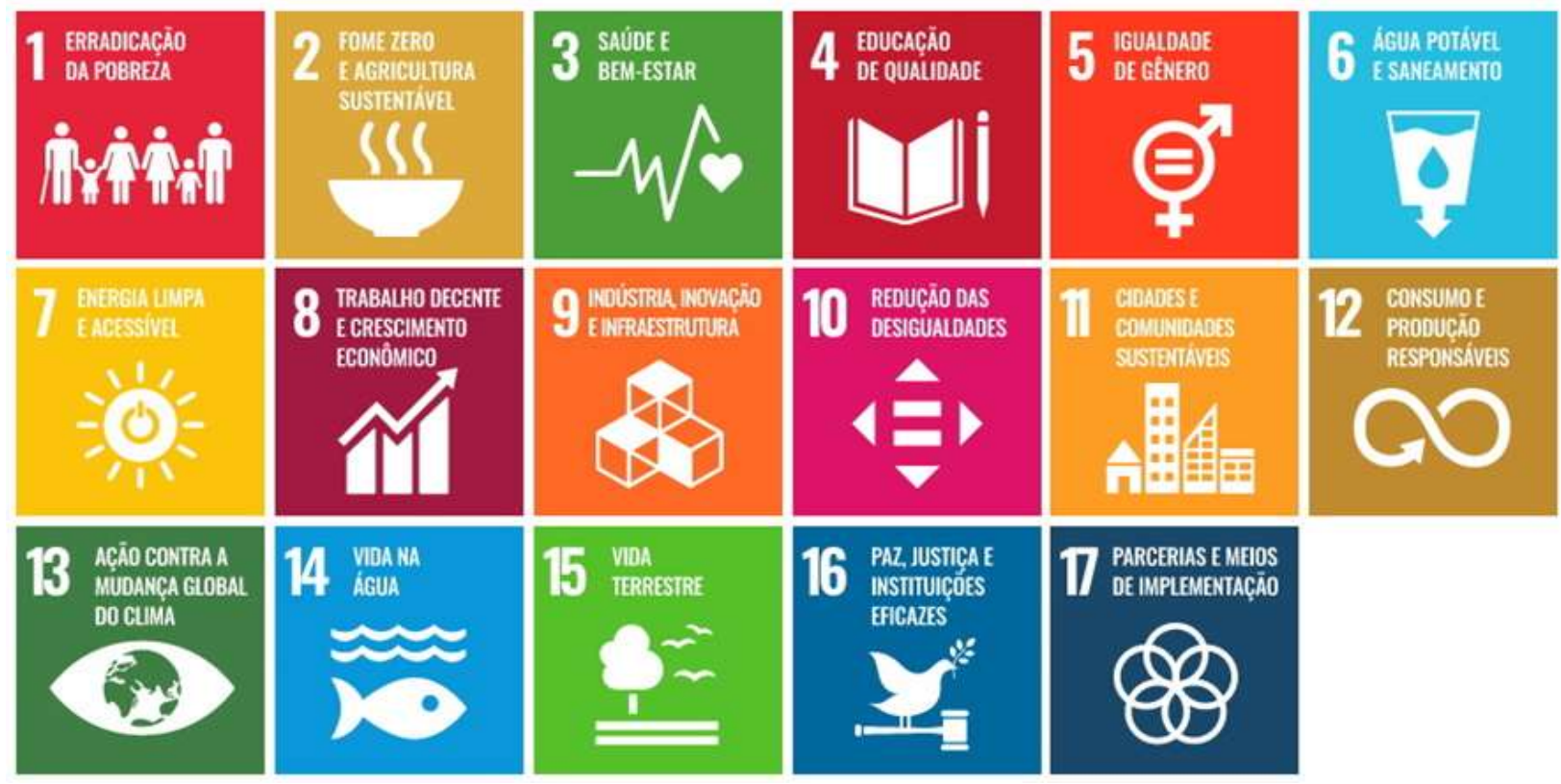

Fonte: Nações Unidas Brasil - Disponível em: https://brasil.un.org/pt-br/sdgs Acesso em: 28 fev. 2021.

Como exemplo de integração, podemos destacar o Objetivo 6 - Água Potável e Saneamento, propondo discussões sobre a abundância da água doce no planeta e sua disponibilidade para o consumo humano, apresentar os problemas relativos ao acesso, saneamento e poluição das águas e propor ações de saneamento adequado para todos, fomentando, assim, o conhecimento interdisciplinar e transdisciplinar.

Por meio do Objetivo 6, os componentes curriculares das duas Áreas de Conhecimento poderão desenvolver suas especificidades, relacionando os saberes com a realidade do estudante, promovendo a conexão da singularidade de cada componente e proporcionando a formação integral do estudante.

Ao integrar as Áreas de Ciências Humanas Sociais e Aplicadas com Ciências da Natureza e Suas Tecnologias por meio do Objetivo 6 de Desenvolvimento Sustentável em um Itinerário Formativo, será possível promover um ensino que contempla as Competências Gerais da BNCC. Destacamos que essas competências são importantes para desenvolver junto aos estudantes os aspectos físicos, cognitivos e socioemocionais, assim como a cidadania e a 
promoção de reflexões ambientais, sociais, políticas, econômicas e culturais. Nesse contexto, citamos as Competências Gerais 5, 6 e 7:

5. Compreender, utilizar e criar tecnologias digitais de informação e comunicação, de forma crítica, significativa, reflexiva e ética nas diversas práticas sociais (incluindo as escolares), para se comunicar, acessar e disseminar informações, produzir conhecimentos, resolver problemas e exercer protagonismo e autoria na vida pessoal e coletiva.

6. Valorizar a diversidade de saberes e vivências culturais e apropriar-se de conhecimentos e experiências que possibilitem entender as relações próprias do mundo do trabalho e fazer escolhas alinhadas ao exercício da cidadania e ao seu projeto de vida.

7. Argumentar com base em fatos, dados e informações confiáveis, buscando formular e defender ideias que respeitem e promovam os direitos humanos, a consciência socioambiental e o consumo responsável em âmbitos local, regional e global. (BRASIL, 2018, p. 9)

Essas competências fortalecem as aprendizagens relacionadas a Cultura Digital, ao Trabalho e Projeto de Vida e a Argumentação, fundamentais para a formação integral do estudante. Citamos também, as Competências Gerais 8,9 e 10, que fomentam a promoção do Autoconhecimento e Autocuidado, da Empatia e Cooperação e da Responsabilidade e Cidadania, conforme excerto abaixo:

8. Conhecer-se, valorizar-se e cuidar de sua saúde física e emocional, compreendendo a si mesmo na diversidade humana e reconhecendo suas emoções e as dos outros, com autocrítica e capacidade para lidar com elas. 9. Exercitar a empatia, o diálogo, a resolução de conflitos e a cooperação, fazendo-se respeitar e promovendo o respeito ao outro e aos direitos humanos, com acolhimento e valorização da diversidade.

10. Agir pessoal e coletivamente com autonomia, responsabilidade, flexibilidade, resiliência e determinação, tomando decisões com base em princípios éticos, democráticos, inclusivos, sustentáveis e solidários. (BRASIL, 2018, p. 9)

Sendo assim, os ODS, integrados as Áreas de Ciências Humanas Sociais e Aplicadas com Ciências da Natureza e Suas Tecnologias, são possibilidades de proporcionar atividades instigantes com os estudantes, capacitando-os a lidar com dilemas da vida estudantil e pessoal, aproximando-os das reflexões da realidade e da atualidade. 


\title{
O ensino de Filosofia, a condição humana e a importância da Declaração Universal dos Direitos Humanos
}

Desde a antiguidade a Filosofia vem se destacando com o desenvolvimento do pensamento humano por meio da reflexão crítico-filosófica aplicada às interações sociais, políticas, históricas, econômicas e culturais.

Olhando os 17 ODS, podemos resgatar a Declaração Universal dos Direitos Humanos (DUDH) e pensar como o ensino de Filosofia, articulado aos demais componentes curriculares das Áreas Ciências Humanas e Sociais Aplicadas, e Ciências da Natureza e suas Tecnologias, na educação básica, podem contribuir para a formação do cidadão ético e responsável, que respeita os Direitos Humanos e a interculturalidade, que combate os preconceitos de qualquer natureza.

Para pensar nessa condição, daremos ênfase à Declaração Universal dos Direitos Humanos, destacando dois artigos para exemplificar a importância dessa integração.

\begin{abstract}
Artigo XXIII - 1. Toda pessoa tem direito ao trabalho, à livre escolha de emprego, a condições justas e favoráveis de trabalho e à proteção contra o desemprego. 2. Toda pessoa, sem qualquer distinção, tem direito a igual remuneração por igual trabalho. 3. Toda pessoa que trabalhe tem direito a uma remuneração justa e satisfatória que lhe assegure, assim como à sua família, uma existência compatível com a dignidade humana, e a qual se acrescentarão, se necessário, outros meios de proteção social.

Artigo XXV - 1. Toda pessoa tem direito a um padrão de vida capaz de assegurar a si e a sua família saúde e bem-estar, inclusive alimentação, vestuário, habitação, cuidados médicos e os serviços sociais indispensáveis, e direito à segurança em caso de desemprego, doença, viuvez, velhice ou outros casos de perda dos meios de subsistência fora de seu controle. 2. A maternidade e a infância têm direito a cuidados e assistência especiais. Todas as crianças nascidas dentro ou fora do matrimônio gozarão da mesma proteção social. (ORGANIZAÇÃO DAS NAÇÕES UNIDAS, 1948)
\end{abstract}

Esses dois artigos estabelecem conexão direta com o Objetivo 8 - Trabalho Decente e Crescimento Econômico, que por sua vez possui relação com a Área de Ciências da Natureza e suas Tecnologias, o que fortalece a interdisciplinaridade e transdisciplinaridade entre as Áreas e possibilita, também, o desenvolvimento da reflexão filosófica. Essas relações, quando estabelecidas, fomentam a construção de 
reflexão crítica em torno dos 17 Objetivos de Desenvolvimento Sustentável (ODS) ancorados na Declaração Universal dos Direitos Humanos (DUDH). Todas essas conexões podem ajudar no desenvolvimento das 10 Competências Gerais da BNCC, das competências específicas de cada Área de conhecimento e suas respectivas habilidades.

No exemplo que trazemos, apontamos reflexões sobre o trabalho e as diferentes condições que os homens são submetidos para realizá-lo. Nesse contexto, consideramos oportuno mencionar a filósofa Hannah Arendt em sua reflexão sobre $A$ Condição Humana, em que critica a modernidade, uma vez que ela parece ter dominado os arados e a consequente superprodução de alimentos, ou seja, supostamente satisfazendo o labor, entendido como sendo a satisfação das necessidades biológicas que possibilitam a condição ótima da vida biológica. Porém, por outro lado, Arendt faz uma crítica amarga ao destacar a ausência de efervescência da vida política.

Aprofundando um pouco mais, podemos estender e aplicar seu discurso no sentido de valorizar a reflexão sobre a pluralidade humana, a liberdade e a participação política. Assim sendo, é oportuno considerar a importância da noção de pluralidade humana:

\begin{abstract}
A pluralidade humana, condição básica da ação e do discurso, tem o duplo aspecto de igualdade e diferença. Se não fossem iguais, os homens seriam incapazes de compreender-se entre si e aos seus ancestrais, ou de fazer planos para o futuro e prever as necessidades das gerações vindouras. Se não fossem diferentes, se cada ser humano não diferisse de todos os que existiram, existem ou virão a existir, os homens não precisariam do discurso ou da ação para se fazerem entender. Com simples sinais e sons, poderiam comunicar suas necessidades imediatas e idênticas. (ARENDT, 2010, p. 188)
\end{abstract}

Falar da pluralidade humana nos remete ao papel da Filosofia, ou melhor, ao trabalho desenvolvido pelo professor de Filosofia na colaboração e formação do estudante para que sejam capazes de identificar, reconhecer e transformar as condições e as contingências que afetam todos na sociedade civilizada.

Então, para desenvolver as competências e habilidades propostas pela Base Nacional Comum Curricular (BNCC), na Área de Ciências Humanas e Sociais Aplicadas, faz-se necessária a compreensão e o desenvolvimento da capacidade de 
articulação com a noção de pluralidade humana em Hannah Arendt. A condição humana requer a identificação e o reconhecimento das igualdades e das diferenças entre todos, para então, o ser humano buscar se igualar nas interações sociais. Logo, a constante reivindicação de um contexto e de uma contingência social que ofereça as liberdades políticas típicas de uma democracia. Afinal, as diferenças se igualam somente no contexto do pluralismo democrático. Assim como, estimular e fazer influenciar a ideia de participação política, pois sem participação política e sem envolvimento e comprometimento político e social, jamais conseguiremos alcançar a plena e necessária sociedade civilizada por meio do desenvolvimento da consciência cidadã, que requer participação e ação política. Nas palavras de Arendt:

É com palavras e atos que nos inserimos no mundo humano; e esta inserção é como um segundo nascimento, no qual confirmamos e assumimos o fato original e singular do nosso aparecimento físico original. Não nos é imposta pela necessidade, como o labor, nem se rege pela utilidade, como o trabalho. Pode ser estimulada, mas nunca condicionada, pela presença dos outros em cuja companhia desejamos estar. (ARENDT, 2010, p. 189).

Assim, a partir dos dois artigos da Declaração Universal dos Direitos Humanos (DUDH), do Objetivo 8 da Agenda 2030 e dos trechos da Condição Humana de Hannah Arendt, temos um exemplo da importância da Filosofia como componente curricular e do papel do professor de Filosofia, para promover as reflexões filosóficas desenvolvendo as competências e habilidades da BNCC de forma articulada com o pensamento filosófico, promovendo a aprendizagem de conceitos filosóficos, da ação política e da atitude ética frente aos desafios sociais, políticos, históricos, econômicos e culturais. Tudo isso de forma articulada, estabelecendo conexão do componente de Filosofia com os demais componentes da Área de Ciências Humanas e Sociais Aplicadas e da Ciência da Natureza e suas Tecnologias. 


\section{Conclusão}

Para concluir, destacamos que os documentos oficiais indicam a fragilidade do ensino de Filosofia no Novo Ensino Médio, estando este garantido apenas dentro da Área de Ciências Humanas e Sociais Aplicadas e no desenvolvimento dos Itinerários Formativos que a contemplarão.

Salientamos que os campos de investigação da atividade filosófica - Ética, Política, Epistemologia, Metafísica, Filosofia da Ciência, Lógica e Estética requerem um tempo de execução extenso. A maneira como o ensino da Filosofia poderá acontecer nos Estados, dividida entre a Parte Comum de 1.800 horas e os Itinerários Formativos de 1.200 horas, nos chama atenção, pois os estudantes terão pouco contato com o componente nessa nova divisão, podendo ter a sua formação integral e cidadã comprometida.

Como vimos na exposição desse artigo, essa proposta de organização do Novo Ensino Médio levará o estudante a ter que fazer escolhas, optando por uma das Áreas de Conhecimento para aprofundar os seus estudos. Esse é um ponto de alerta, pois, ao escolher qualquer Área que não seja a de Ciências Humanas e Sociais Aplicadas, em que momento o estudante terá a oportunidade de tomar contato com questões essenciais que apenas o ensino de Filosofia assegura?

A formação plena do estudante necessita do desenvolvimento de competências e habilidades somadas aos valores e atitudes. Todos os componentes curriculares devem estar a serviço dessa formação, todos são importantes. No entanto, elaboramos esse artigo para apresentar como a Filosofia pode se fazer presente, relacionando-se com as proposições das 10 Competências Gerais da BNCC e com as competências e habilidades da sua Área de Conhecimento e da Área de Ciências da Natureza e suas Tecnologias, ampliando suas possibilidades. Destacamos ainda, que essa presença filosófica também pode se estabelecer com as competências e habilidades da Área de Ciências da Natureza e suas Tecnologias para além dos exemplos das ODS, assim como, ser desenvolvida nas demais Áreas de Conhecimento da BNCC, como a Área de Linguagens e suas Tecnologias e a Área de Matemática e suas Tecnologias. 
Os exemplos apontados nesse artigo, relacionados com a Declaração Universal do Direitos Humanos e com a Agenda 2030 para o Desenvolvimento Sustentável, apontam o fortalecimento da formação do cidadão pleno, íntegro e responsável pela sociedade e pelo planeta.Por meio desses exemplos podemos considerar o quanto o ensino de Filosofia é importante para promover o desenvolvimento das atitudes e das reflexões filosóficas no Ensino Médio.

\section{Referências}

ARENDT, Hannah. A Condição Humana. 11. ed. São Paulo: Forense Universitária, 2010.

BRASIL. Ministério da Educação. Base Nacional Comum Curricular. Brasília, DF, 2018. Disponível em: http://basenacionalcomum.mec.gov.br/. Acesso em: 28 fev. 2021.

BRASIL. Lei 9.394 de 20 de dezembro de 1996. LDB - Lei das Diretrizes e Bases da Educação Nacional.

BRASIL. Lei 13.415 de 16 de fevereiro de 2017. Altera a LDB - Lei das Diretrizes e Bases da Educação Nacional e outras.

BRASIL. Portal Mec - Novo Ensino Médio - perguntas e respostas.Disponível em: http://portal.mec.gov.br/publicacoes-para-professores/30000-uncategorised/40361novo-ensino-medio-duvidas. Acesso em: 28 fev. 2021.

BRASIL. Portaria n 1.432 de 28 de dezembro de 2018. Estabelece os referenciais para elaboração dos itinerários formativos conforme preveem as Diretrizes Nacionais do Ensino Médio.

BRASIL. Resolução $n^{\circ}$ 3, de 21 de novembro de 2018. Atualiza as Diretrizes Curriculares Nacionais para o Ensino Médio.

INSTITUTO REUNA. BNCC Comentada para o Ensino Médio. Disponível em: https://institutoreuna.org.br/o-reuna/. Acesso em: 28 fev. 2021.

ORGANIZAÇÃO DAS NAÇÕES UNIDAS. Agenda 2030. Disponível em: http://www.agenda2030.com.br/. Acesso em: 28 fev. 2021.

ORGANIZAÇÃO DAS NAÇÕES UNIDAS. Declaração Universal dos Direitos

Humanos, 1948. Disponível em: https://www.unicef.org/brazil/declaracao-universaldos-direitos-humanos. Acesso em: 28 fev. 2021. 
KRAWCZYK, N.; FERRETI, C. J. Flexibilizar para quê? meias verdades da "reforma". Revista Retratos da Escola.v.11, n.20, jan./jun. de 2017.

SIMÕES, W. O lugar das Ciências Humanas na "reforma" do ensino médio. Revista Retratos da Escola.v.11, n.20, jan./jun. de 2017.

\section{Notas}

${ }^{1}$ O Instituto Reúna, com o objetivo de subsidiar a implementação da BNCC nos Estados, elaborou um organizador curricular comentado, evidenciando objetos de conhecimento e como cada componente se relaciona com a habilidade. - Disponível em: https://institutoreuna.org.br/o-reuna/. Acesso em: 28 fev. 2021.

${ }^{2}$ A Resolução $n^{\circ}$ 3, de 21 de novembro de 2018 atualiza as Diretrizes Curriculares para o Ensino Médio. Nesta resolução é possível conferir informações essenciais sobre o processo de implementação, onde são apresentadas informações sobre o Objeto e Referencial, a Organização Curricular e Formas de oferta, os Sistemas de Ensino e a Proposta Pedagógica e as Disposições gerais e transitórias.

\section{(1) (1)(9)}

This work is licensed under a Creative Commons Attribution-NonCommercial 4.0 International (CC BY-NC 4.0) 